\title{
THF USE OF THE GRAVER'S POINT IN DISSECTIONS
}

\author{
JOSEPH H. HATHAWAY \\ Department of Anatomy, University of Louisville
}

Last year I had occasion to make some preparations of the inner ear to demonstrate the labyrinth and tympanic cavity and it occurred to me to test the efficiency of the engraver's points as instruments for this kind of dissection. The ease with which excellent results could be obtained by the use of this instrument immediately suggested its practicability in the hands of students for similar purposes. Accordingly it was made a requirement this year that each student's dissceting set should be supplied with a graver's point.

It has been my experience that with the mare usual methods of employing a mallet and chisel for these fine dissections the student, with uncertain technique and judgment, is quite prone to ruin the whole specimen at a single blow. With these engraving instruments, however, it was found to be a very simple and easy matter to guide the students' work and lead them to obtain very perfect results. The results of this year's work with the instrument were decidedly satisfactory, notwithstanding the fact that in a class of ninety there were men quite widely differing in the matter of previous training and endowment with natural talents.

In the dissection of the inner ear, the method of work which was outlined for the students may be briefly stated in the following manner. The student is first required to make himself as well acquainted as possible with the anatomy of the ear by studying the Auzoux models with the aid of his textbook. When this is accomplished he begins the actual dissection of the ear on his cadaver.

The periosteal layer of the dura is removed from the petrous part of the temporal bone, using care not to tear away the great superficial petrosal nerve. With the graver's point a groove is cut transversely to the long axis of the petrous bone and approximately over the course of the superior semicircular canal. The position of this canal is about 8 $\mathrm{mm}$. lateral to the internal acoustic meatus and is indicated by the more or less indistinct arcuate eminence.

This groove is deepened and widened by successive cuts until it opens into the diploë. This diploë occasionally proved confusing to some students as its appearance often suggests a canal. Complete removal of the diploë exposes a rounded ridge of hard bone which gives accurately the position of the superior canal. A V-shaped groove cut along the course of this ridge and gradually deepened, will soon expose the small 
lumen of the canal. Inserting a bristle into the lumen, it is easily opened (1) to it: ampulla in front and backwards to the crus commune behind.

It is next most convenient to open the posterior semicircular canal, starting from the crus commune and cutting awny the bone forming the posterior wall of the canal until its ampulla is reached inferiorly.

A considerable amount of eompact and cancellous bone which lies, lateral to the superior canal, must now be carefully eut away until the upper level of the lateral semicircular canal is reached. To open thi canal the bone forming its upper wall is cut away, thus laying it open from it ampulla back to the erus simplex. This leaves the facial nerve untouehed and uninjured in its position directly beneath this camal.

The semicircular canals having been demonstrated, exposure of the facial nerve is commenced by eutting away the roof of the internal acoustic meatus. The nervo is thus traced as far as the geniculate ganglion and the connection of the great superficial petrosal nerve with the latter is casily demonstrated. The further course of the facial nerve beneath the lateral semicireular eanal is now traced by cutting away the lateral wall of the facial canal.

By turning aside the facial nerve from its position in the internal acoustic moatus, the cochlear norve mav be soen bending forwarls into the tractus spiralis foraninosus. In oreder to expose the cochlea the bone that lies beneath the knee of the facial nerve may be ant away hy using the edge of the graver instead of its point. The basal eoil of the cochlea becomess exposed first and its connection with the vestibule may be demonstrated by the insertion of a bristle. The smaller coils and modiolus may be completely exposed by cutting deepere into the bone in front and medial to the balsil coil.

When these more delicate parts of the internal ear have berm worked out the tegmen tympani is next cut away, using carc not to disturb the ossicles. The chorda tympani is first identified in its position medial to the neck of the malleus and then the bone is completely cut away from it as it passes from the front margin of the tympanie membrane into the petrotympanic fissure.

By the removal of a comsiderable amount of bone posterior and lateral to the horizontal semicircular canal, the remaining portion of the facial nerve is exposed in its downward bend towards the stylo-mastoid foramen. The exposure of the first part of the chorda tympani may now be completed by cutting open its canaliculus backwards from the posterior margin of the tympanic membrane to the point where it leaves the facial nerve.

After the chorda tympani has been completely exposed the structure and relations of the tympanic cavity may be studied. The roof of the cavity and of the cochleariform canal is more completely cut away and the incus carefully removed so as to allow a better view of the cavity. The M. tensor tympani and the auditive tube are also easily traced out.

Suecessful results with the use of the graver's points are best obtained by holding and using the instruments in the same minner as does the engraver. The handle of the instrument is held socurely against the 
palm of the hand and the point pushed forward in the desired course, making, by suecessive euts, a groove in the bone. Attempts to cut too deeply, or chipping dissections, may lead one into difficulties or aceiclent... To prevent slipping and to guide the instrument more accurately it is necessary to brace the hand by holding a finger or thumb against some part of the specimen. It is essential, for good results, that the instrument shall not be too long and so it is often desirable to break off a piece from the shank. Instead of the regulation handle a ehampagne cork is often found an excellent and convenient substitute.

The large variety of shapes in which graver's points may be obtained suggests a great many possibilities for fine dissections in which there are delicate nerves or other structures. The diamond-point graver appears to be the best form, however, for general purposes.

The practical value of this instrument, as adapted to anatomical dissections, may besummed up as follows:

1. It makes possible and practicable a perfect dissection of the middle and inner ear and of similar minute structures. Any of the delicate dissections in Spalteholz's Atlas may be easily reproduced.

2. The student's dissection of the middle and inner ear can be easily and perfectly controlled by the instruetor and aceidents, which might spoil the specoimen, are entirely avoidable.

3. The best and most praetical method for the student to learn the anatomy of the intermal car, and for the orientation of it in relation to the temporal bone and to the head in general, is for him to study firstan aceurate model and then do a perfect and careful disiection upon the carlaver. Such a disiseretion is possible in every detail with the use of the graver's point.

4. With these instruments a perfect dissection of any of the minute structures in bone is quite an easy matter-such as the terminal ramifieations of the dental nerves, the small branches of the trigeminal, facial, glossopharyngeal or vagus nerves and their ganglia; or the dissection of small arteries and museles of the ear or other parts of the head.

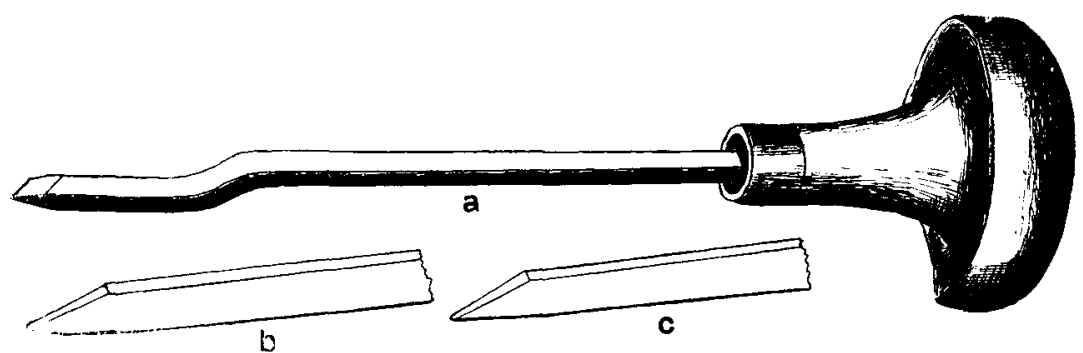

Fig. 1 a, The dianome point graver; b, a point with romeded end for rotting

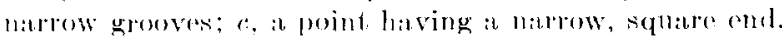




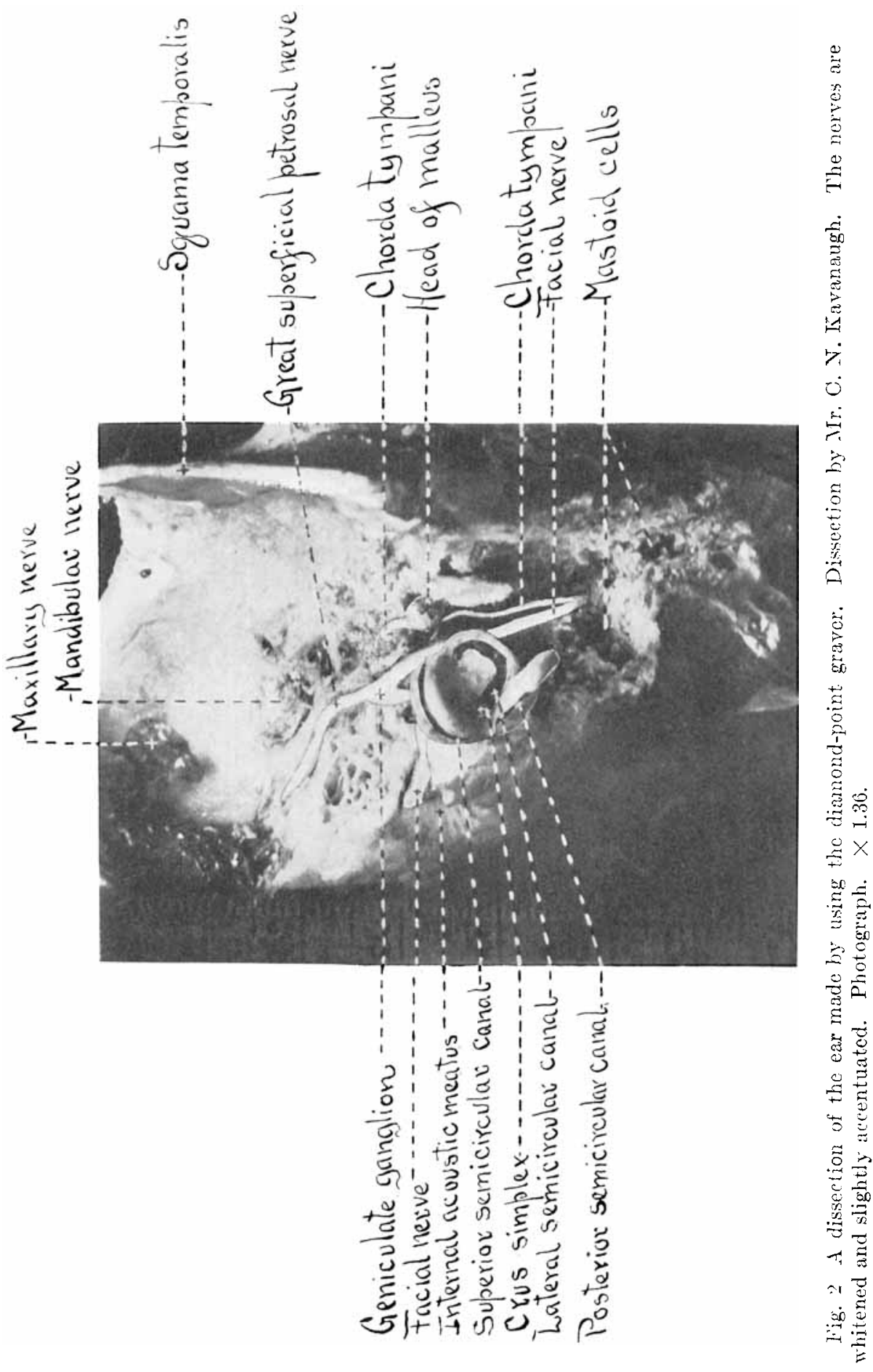




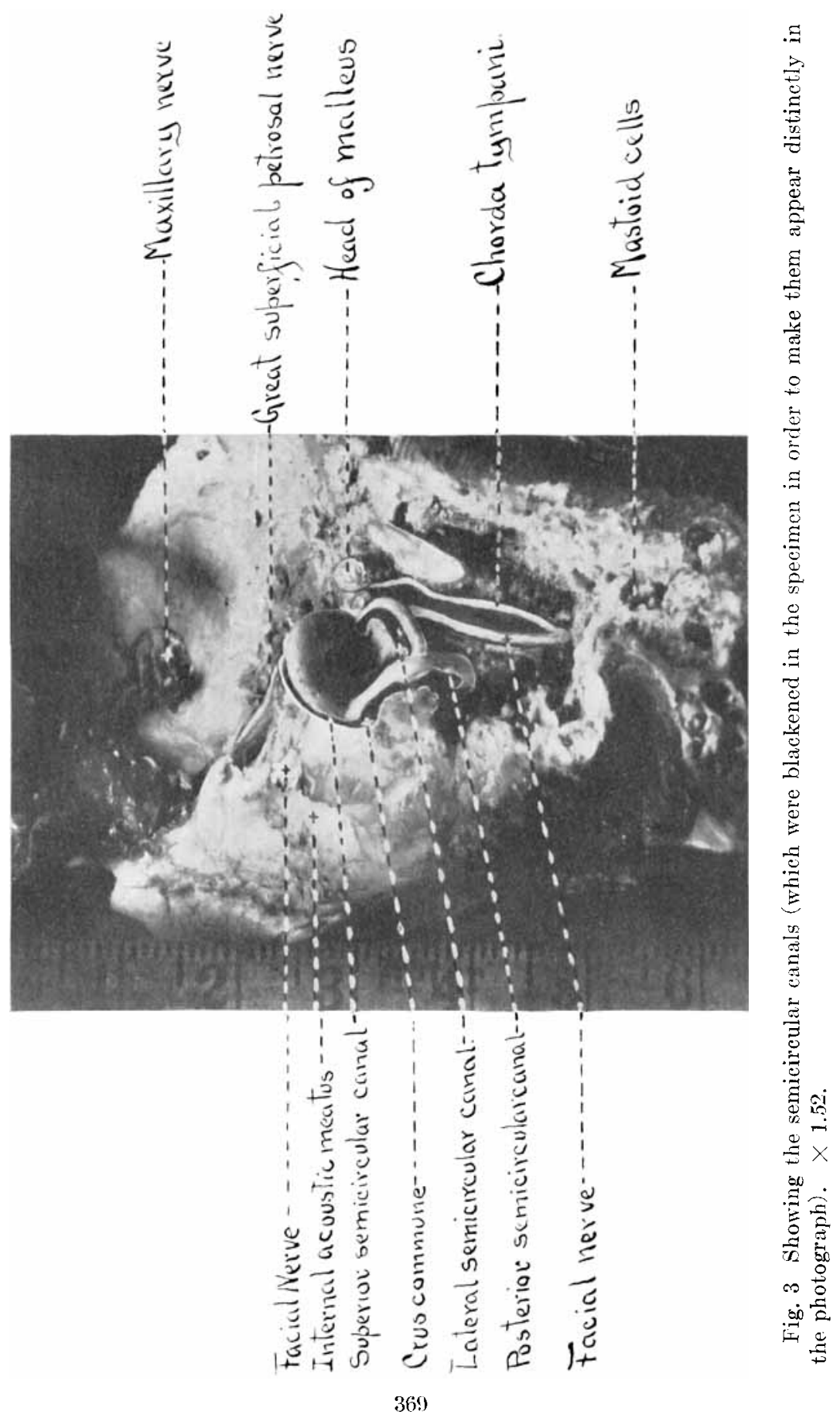




\section{BOOKS RECEIVED}

A TEXT-BOOK OF HEMAN PHYSIOLOGY, including a section on Physiologic Apparatus, Albert P. Brubaker, fourth edition, revised and enlarged, with 1 colored plate and 376 illustrations, 736 pages including Index, 1912, \$3.00. P'. Blakiston's Son and Company, 1012 Walnut s reet, Philadelphia.

COMPARATIVE ANATOMIY OF VERTEBRATES, J. s. Kingsley, with 346 illustrations: 401 pages including Index, 1912, \$2.25. P'. Blakiston's Son and company, 1012 Walnut Street, Philadelphia.

PRAC'TICAL ANATOMY, an exposition of the facts of gross anatomy from the topographical standpoint and a guide to the dissection of the human body, John (3. If eisler, with 366 illustrations, of which 225 are in color. 790 pages including Index, 1912, \$4.50. J. B. Lippineott company, Philadelphia and London. 